\title{
Sex and the nose: human pheromonal responses
}

\author{
Mr Mahmood F Bhutta
}

J R Soc Med 2007;100:268-274

\section{SUMMARY}

The chemosensory functions of the human nose are underappreciated. Traditional teaching is that the sense of smell detects volatile compounds, which may then allow the identification of substances that may be beneficial or harmful - such as good versus putrefied food. However, increasing evidence from research in other animals suggests that olfaction may serve another and more important purpose, that of mate selection in sexual reproduction; indeed, olfaction may be an essential impetus for evolution.

\section{EVOLUTION AND PURPOSE OF OLFACTION}

Chemosensation is the most basic of senses. It can be found in the simplest of life-forms; for example bacteria will release substances into their medium that regulate the reproduction of their colony. ${ }^{1}$ During evolution and in more complex animals, the olfactory neuroepithelium has developed as a specialized area of chemosensation to detect and assess the various compounds in the environment, which may then elicit an appropriate response.

That this is the most basic of our senses is evidenced in humans as much as in other animals by the direct connections of olfactory neurones to the limbic and memory centres of the brain (Figure 1). The limbic system is a phylogenetically very 'old' part of the mammalian brain that governs emotions and behaviours, such as aggression, fear or mating responses. These connections in many animals cause a direct behavioural response to a particular odourant, linked to the memory of that odourant. Indeed the olfactory system may be viewed as an extension of the limbic brain; it is the only sensory system that connects directly with behavioural centres without requiring prior processing of sensory information in other centres (such as the thalamus). ${ }^{2}$ Many of us can think of an odour that instantly evokes a memory: ${ }^{4}$ in many animals these odours also directly evoke a behavioural response.

The compounds that are detected by the olfactory epithelium are not only those that happen to be in the environment. Species also release chemical signals into the environment to communicate their presence and to evoke behavioural responses in other members of their species-

SpR Otolaryngology, Head \& Neck Surgery, Department of ENT, Kettering General Hospital, Rothwell Road, Kettering, Northants NN16 8UZ, UK usually concerned with mating responses. The term 'pheromone' was first coined in the 1950s for a substance secreted by an animal that causes a specific reaction in another animal. ${ }^{5}$ The actions and mechanisms of pheromones have been widely studied in animals and with recent advances in molecular and cell biology the scope and importance of olfactory communication is only just being realized.

\section{PHEROMONE COMMUNICATION IN ANIMALS}

Pheromone communication is known to exist in almost all social animals,${ }^{6}$ from ants and moths to goldfish and turtles, snakes and salamanders, kangaroos and dogs ${ }^{7}$. The most widely studied animal, however, is the laboratory mouse, where several pheromonal responses have been characterized. For example:

- Menstrual cycles of female mice housed in the absence of a male will slow and eventually stop (the Lee-Boot effect $\left.^{8}\right)$;

- Menstrual cycles of female mice will restart and synchronize when subsequently exposed to a male (the Whitten effect ${ }^{9}$ );

- Females housed with a male show an earlier onset of puberty than those housed without (the Vandebergh effect ${ }^{10}$ );

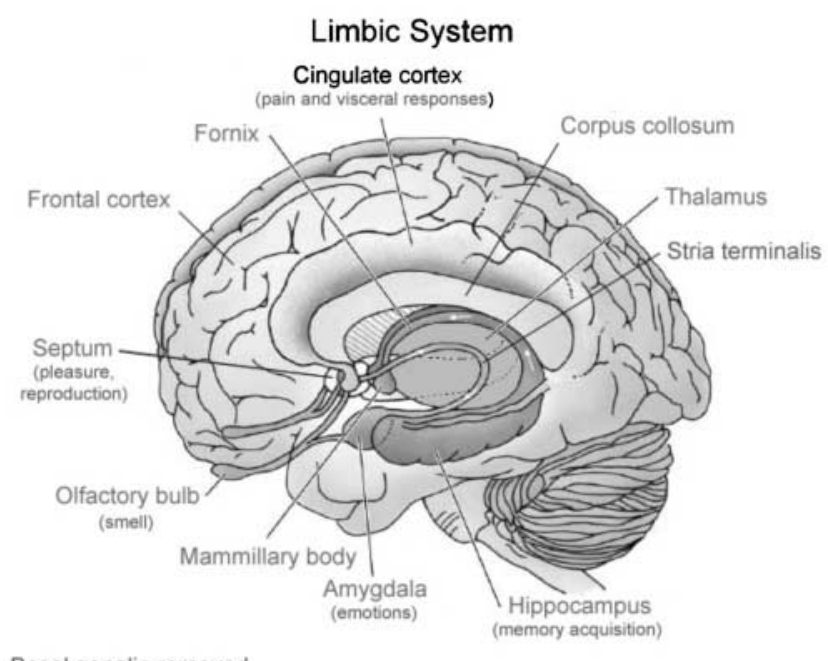

Basal ganglia removed

Figure 1 The limbic system and olfactory connections ${ }^{3}$ 


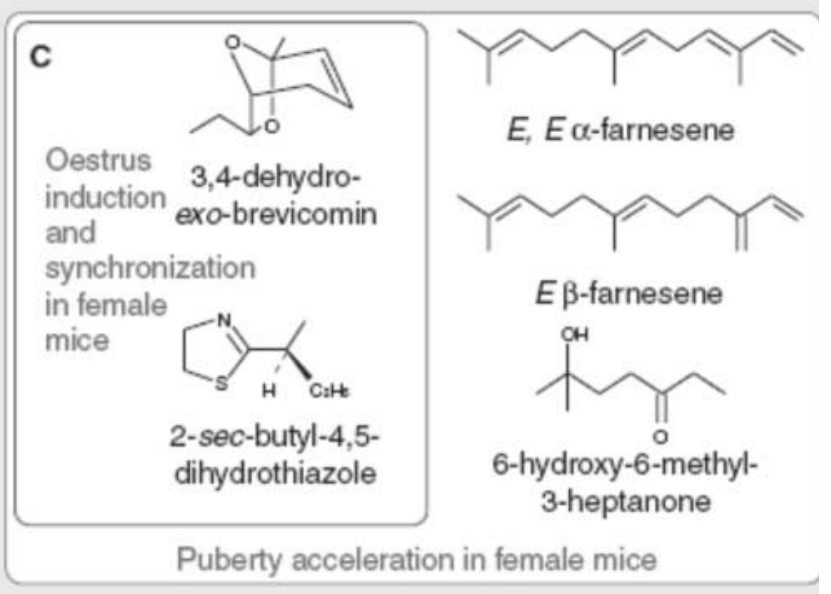

Figure 2 Mouse urinary pheromones. Adapted from Brennan and Keverne $^{13}$

- In a pregnant mouse, housing with a fertile male other than that which impregnated the female will cause termination of the pregnancy (the Bruce effect ${ }^{11}$ ).

These responses have been shown to be due to a variety of extractable volatile compounds found in mouse bodily fluids, in particular urine (Figure 2). ${ }^{12,13}$ The general importance of urine as a pheromone vehicle in many mammals is obvious to anyone who has taken the dog for a walk; it is an excellent means of distributing information within a species, whether the purpose be marking territory or attracting a mate. The method of detection of pheromones has also been characterized. In addition to the traditional olfactory system, often termed the main olfactory system, in the vast majority of terrestrial animals an accessory olfactory system has also evolved specifically to detect pheromones as opposed to other environmental odourants. ${ }^{7,14}$

\section{THE ACCESSORY OLFACTORY SYSTEM}

The accessory olfactory system consists of the vomeronasal organ, a bilateral tubular structure on the anterior nasal septum, and its projections to the accessory olfactory bulb, lying adjacent to but separate from the main olfactory bulb (Figure 3). Information from here is projected to the vomeronasal amygdala and from there to other centres, in particular the hypothalamus; hence behavioural and endocrine responses may be invoked. The vomeronasal organ has its own set of receptors, specifically for pheromones, which are distinct from the main olfactory system receptors ${ }^{15}$ and are ultrasensitive ${ }^{16}$ (Figure 4).

There is also a further structure of the accessory nasal system, the nervus terminalis or 'cranial nerve 0' as it has been termed (it was not recognized when cranial nerves were first numbered). This nerve has been little studied, but it is known to be highly conserved across all vertebrates and to secrete gonadotropin releasing hormone hormone, with effects on reproductive endocrinology. ${ }^{17}$ Further research on this mysterious nerve is awaited.

\section{INDIVIDUAL PHEROMONES AND THE MHC}

There is a further layer of complexity in olfactory communication. In evolutionary terms there is little advantage for an animal to simply communicate its species and specify its sex with pheromones. While this may invoke the responses described above, a much more powerful tool is the use of pheromones to specify an individual member of a species; such unique coding will allow an individual response to a set of genes over those of another. Such a system does indeed exist, and the coding may arise from the major histocompatibility complex (MHC). ${ }^{18}$

The MHC is a set of proteins expressed on cellular surfaces that uniquely specifies that individual, and aids in recognition of self from non-self in immune responses. Continual diversity in the MHC through multiple allelic combinations is thought to be central to the success of sexual reproduction; variation in the immune system
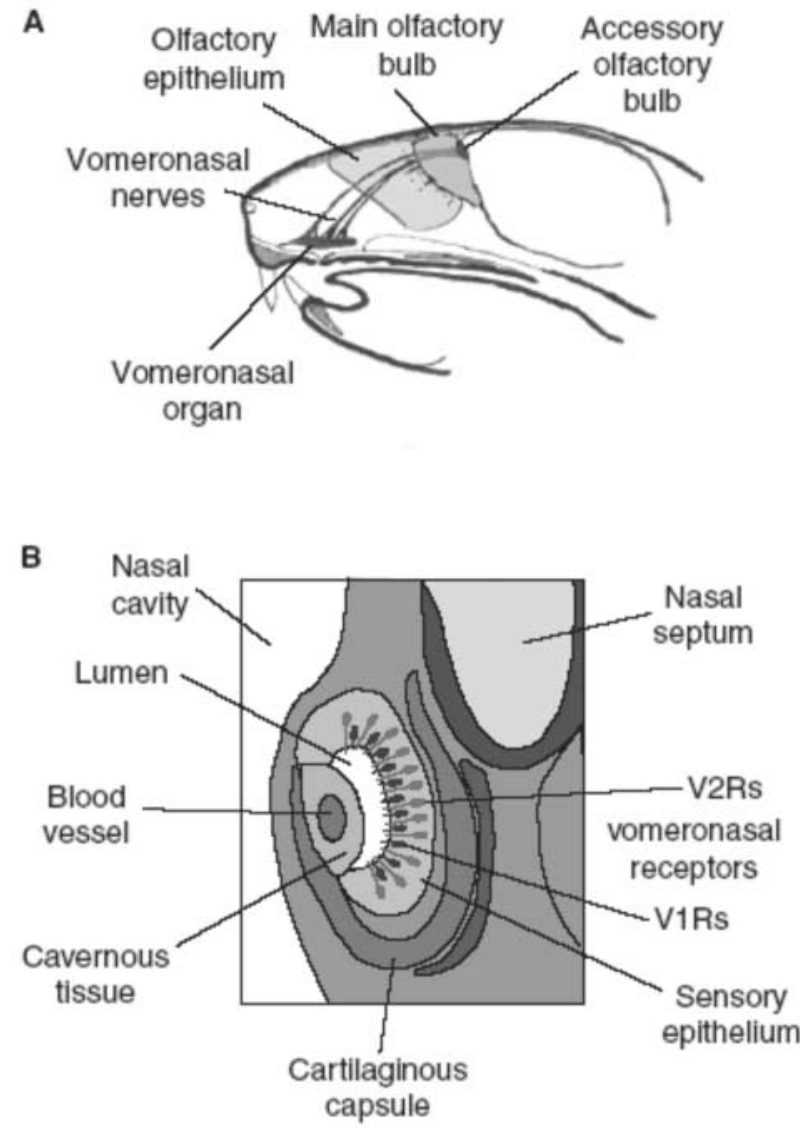

Figure 3 The vomeronasal system in the mouse. Adapted from Brennan and Keverne. ${ }^{13} \mathrm{~A}$ : Saggital section of the main and vomeronasal olfactory systems. The vomeronasal receptors project to the accessory olfactory bulb. B: Coronal section of the vomeronasal organ. Alterations in flow in the blood vessel change the lumen of the organ and pump stimuli in and out. 

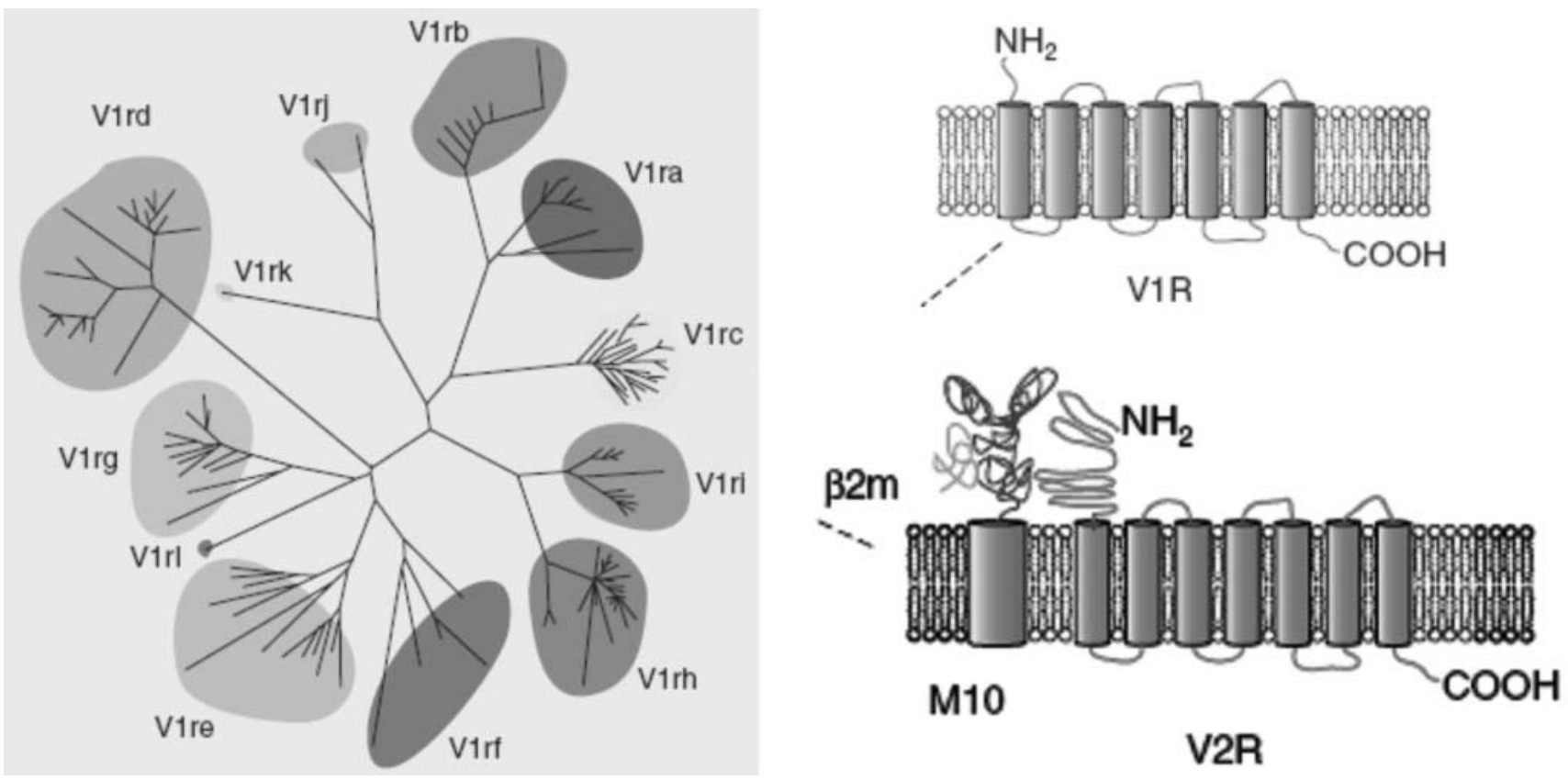

Figure 4 The vomeronasal receptor gene family, and structure of V1R and V2R receptors. Adapted from Brennan and Keverne ${ }^{13}$

creates a moving target for any potential pathogen. ${ }^{19} \mathrm{MHC}$ allele combinations are found to be more diverse than would be expected by chance alone, implying that there is a mechanism of selecting a mate with a differing MHC from ones own, to avoid inbreeding. Such a mechanism of mate selection has been demonstrated in mice, ${ }^{20,21}$ which will preferentially choose mates that express different MHC alleles to themselves. Again, pheromone odorants in urine appear to be the main method of such communication in mice. ${ }^{18,22}$

The exact mechanism of MHC-specific odourant recognition is still being elucidated. Current hypotheses suggest that proteins that are bound to the peptide-binding groove of the MHC may provide the odourant. Each MHC will preferentially bind a different peptide sequence, thereby giving a unique set of protein fragments bound to MHC for each individual. When the MHC-peptide complex is subsequently shed during cellular turnover, these protein fragments are excreted in bodily fluids, perhaps being made volatile by the action of commensal microflora, giving a unique protein fragment odour which is linked to the original MHC constitution of the animal. ${ }^{18}$ Where these peptide fragments are detected is still contested. The finding of expression of MHC fragments in the VCR2 vomeronasal receptor sparked much excitement that this may be the site, ${ }^{23}$ but the significance of this finding is now uncertain. ${ }^{17}$

\section{A NEW IMPORTANCE TO OLFACTION?}

Many of these findings have only been made in the last few years with improvements in molecular technology, and the implies that the MHC constitution of an individual member of a species can be detected from its odour, and that that information can be used by the odour detector to determine whether or not to mate with the carrier to diversify the MHC alleles in its offspring, and consequently improve the function of the offspring's immune system and survival. Then olfaction becomes a central component to the success and the evolution of a species; a role of import that few would have credited only a few years ago.

Is this of any relevance for human rhinology? As a species we are of developed intelligence and reasoning, which many see as negating the biological influences on behaviour seen in 'lower order' animals. But often we are 'speciest' in our view of ourselves. The effects of odour on human reproduction were suggested in medieval folklore, ${ }^{6}$ and in modern times one has only to look at the multibillion pound perfume industry to see obvious evidence that there must be some association between odour and human sexual attraction. Research in this area is surprisingly sparse, but where it has been undertaken there is evidence that humans produce pheromones, can detect pheromones, and show behavioural and endocrine responses to pheromones. ${ }^{24}$

\section{PRODUCTION OF HUMAN PHEROMONES}

In other animals pheromones are found in various excreted bodily fluids, from where they are volatilized. The most frequent source in other mammals is urine, but due to biological and social changes humans usually find the smell of urine unpleasant and do not search it for olfactory clues. ${ }^{6}$ This is not to say that humans do not excrete pheromones 
into their urine: mice can identify an individual from human urine, ${ }^{25}$ implying that MHC-specific odorants must be present. Recently it has been reported that dogs can detect the presence of bladder cancer from human urine, ${ }^{26}$ and it has been suggested this may be due to alterations in urinary odorants caused by MHC changes in oncotic cells. ${ }^{27}$

So are there any sources of human pheromones that other humans may actually smell? Pheromones have been found in human smegma and vaginal secretions and, more importantly, in human apocrine glands. ${ }^{6}$ The apocrine glands are modified sweat glands that are present in the areas that develop post-pubertal hair - the axillary and pubic regions - and their function is predominantly odour secretion. ${ }^{28}$ The specific development of hair in these regions (in our otherwise largely naked bodies) is thought to aid the dispersal of odorants in sexually mature humans. Hair provides a warm environment where the action of commensal bacteria can volatilize the precursor molecules released from apocrine glands. ${ }^{29}$ The responsible odorants have still to be demonstrated, ${ }^{24}$ but both androgen-based volatile steroids ${ }^{28}$ and MHC constituents ${ }^{30}$ can be found in axillary secretions (Figure 5).

\section{DETECTION OF HUMAN PHEROMONES}

Based upon animal studies, the vomeronasal organ would be hypothesized to be the site of pheromone detection in humans. However, although the vomeronasal organ is found in humans ${ }^{31}$ it is thought to be non-functional ${ }^{32}$ as the vomeronasal receptor and signal transduction genes are pseudogenes in $\operatorname{man}^{33,34}$ and the accessory olfactory neuronal connections degenerate during human foetal development. ${ }^{7,35}$

However, this need not mean that there is no method of pheromone detection in humans. Recent work suggests there may have been too much emphasis placed upon the accessory olfactory system as the means of pheromone detection and response. There is evidence from other mammals that pheromone responses occur without the vomeronasal organ, ${ }^{36,37}$ and that the main olfactory systems may in fact play a complementary role in pheromone detection. ${ }^{13,38}$ Transcripts of the V1RL1 vomeronasal receptor are found in human olfactory mucosa, ${ }^{39}$ and this may reflect the fact that in humans (and some other mammals) the accessory olfactory system has been absorbed into the main olfactory system. The main olfactory system certainly has the capacity - the surface area of human olfactory epithelium is $22 \mathrm{~cm}^{3}$ and it expresses over 1000 putative odourant receptors $(1 \%$ of all expressed genes), ${ }^{40,41}$ which through combinatorial activation is capable of detecting around 10000 odorants.

\section{PHEROMONE RESPONSES IN HUMANS}

Of course the production of human pheromones and evidence that they can be detected may just be evolutionary

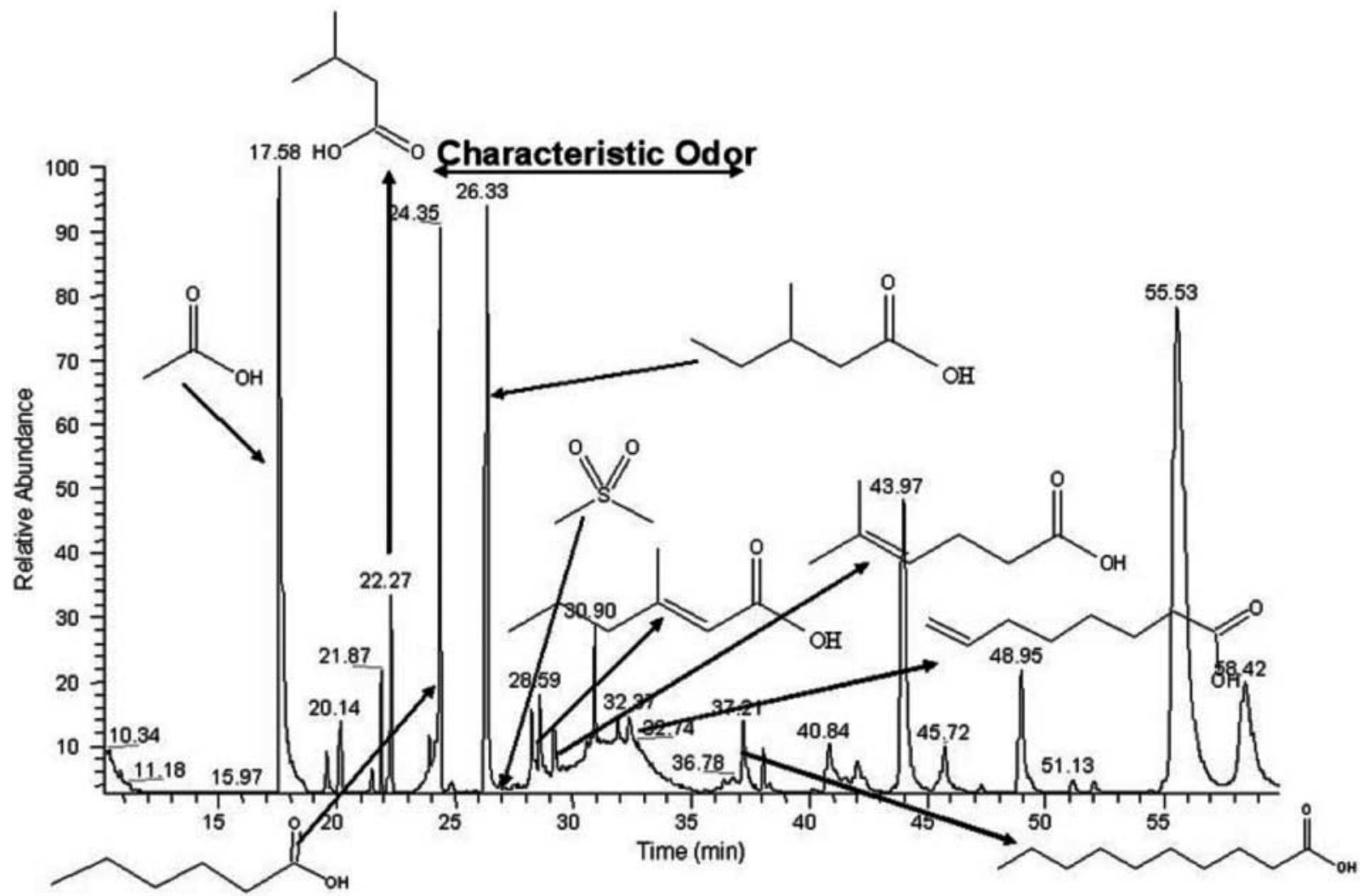

Figure 5 Gas chromatogram of human male axillary secretions ${ }^{24}$ 


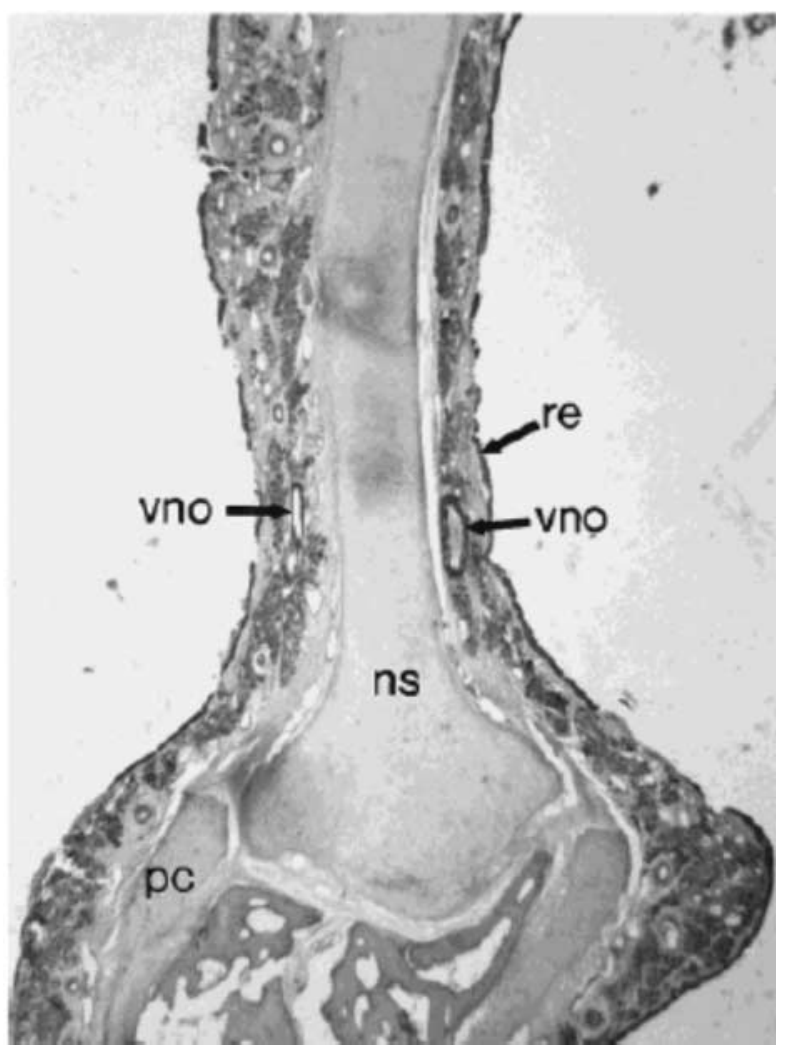

Figure 6 Human vomeronasal organ (vno) in coronal section of the nasal septum (ns) of a $\mathbf{7 6}$ year old male. ${ }^{31} \mathrm{pc}$, paraseptal cartilage; re, respiratory epithelium

relics; these findings are irrelevant if humans do not actually show any responses to pheromones. There is unambiguous evidence that they do.

Most experiments have been undertaken using odours collected from the axilla by a T-shirt worn over several days. As early as 1976, both Russell ${ }^{42}$ and Wallace ${ }^{43}$ showed that people can determine the sex of another person through their odour. This effect is probably mediated by the volatile steroids found in axillary secretions, but what is even more interesting is the effect these secretions may be responsible for. Somewhat analogous to the studies in laboratory mice, axillary extracts from men make the ovulatory cycles of women more regular. ${ }^{44}$ It has also been shown that the same extracts advance the release of luteinizing hormone in women by around $20 \% ; 45$ this is the hormone that causes ovulation and the finding could therefore explain the observed effect on ovulatory cycles. Savic has demonstrated that androgenous odours stimulate the ventromedial hypothalamus in women (but not men) ${ }^{46}$ (Figure 7). This is an area that is known to be associated with copulatory functions in primates; ${ }^{48}$ it is interesting to note that gonadotropin releasing hormone, which stimulates luteinizing hormone release, is released from neurones in the basomedial hypothalamus nearby.
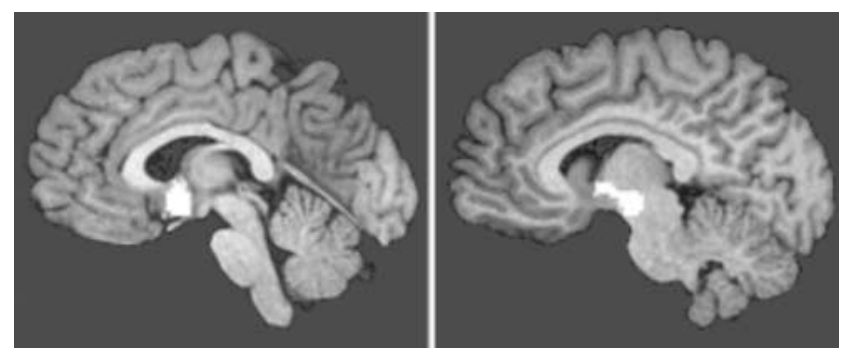

Figure 7 Differential activation of the brain by human sex analogues. Activated areas are shown in white. Adapted from Savic ${ }^{47}$ A: Activation of female anterior hypothalamus by 4,16-androstadien-3-one (AND). This activation is not seen in males. B: Activation of male hypothalamus by oestra-1,3,5(10),16-tetraen-3-ol (EST). This activation is not seen in females

on ovulation in female humans, possibly through the release of gonadotropin releasing hormone and consequently luteinizing hormone. It is interesting to also note the finding that levels of androgenous odorants are linked to perceptions of sexual attractiveness by women, ${ }^{49}$ and that women say they feel more relaxed in the presence of male axillary extracts. ${ }^{45}$ Furthermore, there are variations in the sensitivity of females versus males to masculine odorants: women can smell the musk-like compound exaltolide at a concentration 1000 times lower than men $^{50}$ (some men may be unable to smell it at all ${ }^{51}$ ), and the sensitivity is highest in the pre-ovulatory or ovulatory phases of the menstrual cycle. ${ }^{52}$

There are other effects too, on men from the odour of women, and also intra-sex pheromone responses. In his studies of brain activation, Savic also showed that the dorsomedial and thalamic nucleus of men (but not women) was activated by the smell of the oestrogen based compound $\mathrm{EST}^{46}$ (Figure 7), an area regulating penile erection in primates. ${ }^{48}$ Men rate the odour of both axillary ${ }^{53,54}$ and vaginal $^{55}$ secretions of women as more pleasant when secreted during the pre-ovulatory or ovulatory phase of their menstrual cycle, perhaps a means of detecting fertility. McClintock noticed whilst a student that her menstrual cycle synchronized with her co-habiting female friends, an effect she proved $^{56}$ and was subsequently shown to be due to female axillary extracts. ${ }^{57}$ It is thought that there is a 'driver' female ${ }^{58}$ to which cohabiting women either accelerate or retard their menstrual cycle to synchronize, ${ }^{57}$ although this is debated. ${ }^{59}$ Furthermore, odorants from the breasts of lactating women have been shown to disrupt the menstrual cycle of nulliparous women (the breast is itself a modified apocrine sweat gland). ${ }^{60}$ The reasons for these effects on the menstrual cycle are uncertain; perhaps these responses are of competing biological fertility between women.

Humans can also distinguish an individual from their odour rather than just whether they are male or female. Again using sweaty T-shirts, research has shown that people 
can recognize their own odour ${ }^{42}$ and that of their own kin. ${ }^{61}$ Several studies in babies of only a few weeks old have demonstrated that they can identify, and are attracted to, both the axillary ${ }^{62}$ and the breast odours ${ }^{42,63}$ of their own mother but not of other mothers, and that this is not based upon memory of that odour. Mothers too can recognize the odour of their own baby. ${ }^{64}$ This suggests a mechanism of recognition of kin in humans, and from animal studies MHC-based olfactory signalling would be the plausible mechanism.

If humans can detect an MHC-specific odour, then do humans - like other animals - utilize this in mate selection? ${ }^{65}$ The answer is that we probably do. Several studies have shown that humans rate the axillary odour of MHC dissimilar people as more pleasant than those who share MHC alleles. ${ }^{66,67}$ This effect is not found in women taking the oral contraceptive pill, implying this ability is linked to fertility. One study suggested that it was variance from paternally inherited MHC alleles that was most important for women when choosing a mate, ${ }^{68}$ but this has yet to be confirmed. These are not theoretical determinants of mate choice: research corroborates that we are more likely to choose a mate that is dissimilar in MHC expression than would be expected by chance alone. ${ }^{69}$

Furthermore, several studies have shown that women are far better at odour detection than men. ${ }^{70,71}$ It is biologically more important for a woman to choose the correct mate than a man, as women have a much larger parental investment; ${ }^{72}$ their better sense of smell may reflect this.

Recently an even more unexpected potential role for olfactory receptors has emerged. The sperm of several mammalian species have been known to express olfactory receptors ${ }^{73}$ and Spehr has shown that these are involved in sperm chemotaxis in humans. ${ }^{74}$ Olfactory receptors may guide us not only to the correct choice of sexual partner, but may also guide our gametes to fertilization.

\section{CONCLUSION}

Olfaction as a sensory modality in humans has declined in importance subsequent to the evolution of trichromatic vision, and perhaps even more with the use in contemporary society of perfumes and deodorants to disguise our body odours. However, emerging evidence shows that it may play a far more important role than we suppose, and that in common with other animals it may be involved in endocrine regulation, behavioural responses and in determining when, how and with whom we choose to reproduce. The research in this field remains sparse, and the potential implications of these findings on people clinically afflicted with nasal blockage or anosmia have not been investigated, but could be significant.

\section{REFERENCES}

1 Bassler BL. Small talk. Cell-to-cell communication in bacteria. Cell 2002;109:421-4

2 Carpenter MB. Core Text of Neuroanatomy $4^{\text {th }}$ edn. 1991 Baltimore:Williams and Wilkins

3 Image from www.colorado.edu

4 Herz RS, Engen T. Odor memory:review and analysis. Psychosom Bull Rev 1996;3:300-13

5 Karlson P, Luscher M. 'Pheromones':a new term for a class of biologically active substances. Nature 1959;183:55-6

6 Comfort A. Likelihood of human pheromones. Nature 1971;230:432-3

7 Meisami E, Bhatnagar KP. Structure and diversity in mammalian accessory:olfactory bulb. Microsc Res Tech 1998;43:476-99

8 Van der Lee S, Boot LM. Spontaneous pseudopregnancy in mice. Acto Physiol Pharm Neerland 1955;4:422-44

9 Whitten WK. Ocuurence of anestrus in mice caged in groups. J Endocrinol 1959;18:102-7

10 Vanderbergh JG, Whitsett JM, Lonabard JR. Partial isolation of a pheromone accelerating puberty in female mice. J Reprod Fertil $1975 ; 43: 515-23$

11 Bruce HM. A block to pregnancy in the mouse caused by proximity of strange males. J Reprod Fertil 1960;1:96-103

12 Dulac C, Torello AT. Molecular detection of pheromone signals in mammals:from genes to behaviour. Nature Rev Neurosci 2003;14:55162

13 Brennan PA, Keverne EB. Something in the air? New insights into mammalian pheromones. Current Biology 1994;14:R81-R89

14 Eisthen HL. Phylogeny of the vomeronasal system and of receptor cell types in the olfactory and vomeronasal epithelia of verebrates. Microsc Res Tech 1992;21:1-21

15 Rodriguez I. Pheromone receptors in mammals. Hormones and Behavior 2004;46:219-30

16 Leinders-Zufall $\mathrm{T}$, Lane AP, Puche AC, et al. Ultrasensitive pheromone detection by mammalian vomeronasal neurons. Nature 2000;405:792-6

17 Schwanzel-Fukuda M, Pfaff DW. Structure and function of the nervus terminalis. In: Doty RL (ed). Handbook of Olfaction and Gustation. New York: Marcel Dekker, 1995:835-64

18 Boehm T, Zufall F. MHC peptides and the sensory evaluation of genotype. Trends Neurosci [In press]

19 Hamilton WD, Axelrod R, Tanese R. Sexual reproduction as an adaptation to resist parasites (a review). Proc Natl Acad Sci 1990;87:3566-73

20 Penn D, Potts W. How do major histocompatability complex genes influence odor and mating preferences? Adv Immunol 1998;68:411-35

21 Yamazaki K, Beauchamp GK, Curran M, Bard J, Boyse EA. Parentprogeny recognition as a function of MHC odortype identity. Proc Natl Acad Sci USA 2000;97:10500-2

22 Leinders-Zufall T, Brennan P, Widmayer P, et al. MHC class I peptides as chemosensory signals in the vomeronasal organ. Science 2004;306:1033-7

23 Hedge AN. MHC molecules in the vomeronasal organ:contributors to pheromonal discrimination? Trends Neurosci 2003;26:646-50

24 Wysocki CJ, Preti G. Facts, fallacies, fears and frustrations with human pheromones. Anat Rec 2004;281A:1201-11

25 Ferstl R, Eggert F, Westphal E, Zavazava N, MÏller-Ruchholtz W. MHC-related odors in human. In: Doty RL (ed). Chemical signals in vertebrates VI. NewYork: Plenum, 1992: 205-11

26 Willis CM, Church SM, Guest CM, et al. Olfactory detection of human bladder cancer by dogs: proof of principle study. BMJ 2004;329:712-4 
27 Balseiro SC, Correia HR. Is olfactory detection of human cancer by dogs based on major histocompatibility complex dependent odour components? A possible cure and a precocious diagnosis of cancer. Med Hypoth 2006;66:270-2

28 Gower DB, Ruparelia BA. Olfaction in humans with special reference to odorous 16-androstenes: their occurrence, perception, and possible social, psychological, and sexual impact. J Endocrinol 1993;137:167-87

29 Leyden JJ, McGinley KJ, Hoelzle K, Labows JN, Kligman AM. The microbiology of the human axillae and its relation to axillary odors. $J$ Invest Dermatol 1982;77:413-416

30 Zavazava N, Wobst B, Ferstl R, Muller-Ruchholtz W. Soluble MHC class 1 molecules in human body fluids. J Clin Lab Anal 1994;8:432436

31 Smith TD, Siegel MI, Burrows AM, et al. Searching for the vomeronasal organ of adult humans: preliminary findings on location, structure, and size. Micros Res Tech 1998;41:483-91

32 Doty RL. Olfaction. Ann Rev Psychol 2001;52:423-52

33 Rodriguez I, Mombaerts P. Novel human vomeronasal receptorlike genes reveal species-specific families. Curr Biol 2002;12:R409-R411

34 Liman ER, Innan H. Relaxed selective pressure on an essential component of pheromone transduction in primate evolution. Proc Natl Acad Sci USA 2003;100:3328-32

35 Boehm N, Roos J, Gasser B. Luteinizing hormone-releasing hormone (LHRH)-expressing cells in the nasal septum of human fetuses. Brain Res Dev Brain Res 1994;82:175-180

36 Dorries KM, Adkins RE, Halpern BP. Sensitivity and behavioral responses to the pheromone androstenone are not mediated by the vomeronasal organ in domestic pigs. Brain Behav Evol 1997;49:53-62

37 Hudson R, Distel H. Pheromonal release of suckling in rabbits does not depend on the vomeronasal organ. Physiol Behav 1986;37:123-9

38 Restrepo D, Arellano J, Oliva AM, Schaefer ML, Lin W. Emerging views on the distinct but related roles of the main and accessory olfactory systems in responsiveness to chemosensory signals in mice. Horm Behav 2004:46:247-56

39 Rodriguez I, Greer CA, Mok MY, Mombaerts,P. A putative pheromone receptor gene expressed in human olfactory mucosa. Nat Genet 2000;26:18-9

40 Doty RL. Cranial nerve I: olfaction. In: Goltz CG, Pappert Ej (eds). Textbook of Clinical Neurology. Philadelphia: Saunders, 1998:90-101

41 Buck L, Axel R. A novel multigene family may encode odorant receptors:a molecular basis for odor recognition. Cell 1991;65:175-87

42 Russell MJ. Human olfactory communication. Nature 1976;260:520-2

43 Wallace P. Individual discrimination of human by odour. Physiol Behav 1977; 19:577-9

44 Cutler WB, Preti G, Krieger AM, Huggins GR, Garcia CR, Lawley HJ. Human axillary secretions influence women's menstrual cycles:the role of donor extract from men. Horm Behav 1986;20:463-73

45 Preti G, Wysocki CJ, Barnhart KT, Sondheimer SJ, Leyden JJ. Male axillary extracts contain pheromones that affect pulsatile secretion of luteinizing hormone and mood in women recipients. Biol Reprod 2003;68:2107-13

46 Savic I, Berglund H, Gulyas B, Roland P. Smelling of odorous sex hormone-like compounds causes sex-differentiated hypothalamic activations in humans. Neuron 2001;31:661-8

47 Savic I. Imaging of brain activation by odorants in humans. Curr Opin Neurobiol 2002;12:455-61

48 Oomura Y, Aou S, Koyama Y, Fujita I, Yoshimatsu H. Central control of sexual behavior. Brain Res Bull 1988;20:670-83

49 Kirk-Smith MD, Booth DA, Caroll D, Davies P. Human social attitudes affected by androstenol. Res Comm Psychol Psychiatr Behav 1978;3:379-84
50 Doty RL, Snyder PJ, Huggins GR, Lowry LD. Endocrine, cardiovascular and psychological changes during the human menstrual cycle. J Comp Physiol Psych 1981;95:45-60

51 Good PR, Geary N, Engen T. The effect of estrogen on odor detedtion. Chem Sens Flav 1976;2:45-50

52 Vierling JS, Rock J. Variations of olfactory sensitivity to exaltolide during the menstrual cycle. J Appl Physiol 1967;22:311-5

53 Poran NS. Cyclic attractivity of human female odours. Adv Biosci 1994;93:555-60

54 Singh D, Bronstad PM. Female body odour is a potential cue to ovulation. Proc Biol Sci 2001;268:797-801

55 Doty RL, Ford M, Preti G, Huggins GR. Changes in the intensity and pleasantness of human vaginal odors during the menstrual cycle. Science $1975 ; 190: 1316-8$

56 McClintock MK. Menstrual synchrony and suppression. Nature 1971;229:244-5

57 Preti G, Cutler WB, Huggins GR, Garcia CR, Lawley HJ. Human axillary secretions influence women's menstrual cycles:the role of donor extracts from women. Horm Behav 1986;20:474-82

58 Stern K, McClintock MK. Regulation of ovulation by human pheromones. Nature 1998;392:177-9

59 Weller L, Weller A. Human menstrual synchrony:a critical assessment. Neurosci Biobehav Rev 1993;17:427-39

60 Jacob S, Spencer NA, Bullivant SB, Sellergren SA, Mennella JA, McClintock MK. Effects of breastfeeding chemosignals on the human menstrual cycle. Hum Reprod 2004;19:422-9

61 Porter RH, Moore JD. Human kin recognition by olfactory cues. Physiol Behav 1981;27:493-5

62 Cernoch JM, Porter RH. Recognition of maternal axillary odors by infants. Child Develop 1985;56:1593-8

63 Varendi H, Porter RH. Breast odour as the only maternal stimulus elicits crawling towards the odour source. Acta Paediatr 2001;90:372-5

64 Kaitz M, Good A, Rokem AM, Eidelman AI. Mothers' recognition of their newborns by olfactory cues. Dev Psychobiol 1987;20:587-91

65 Wedekind C, Penn D. MHC genes, body odours, and odour preferences. Nephrol Dial Transplant 2000;15:1269-71

66 Wedekind C, Seebeck T, Bettens F, Paepke AJ. MHC-dependent mate preferences in humans. Proc R Soc Lond B 1995;260:245-9

67 Wedekind C, Furi S. Body odour preferences in men and women:do they aim for specific MHC combinations or simply heterozygosity? Proc $R$ Soc Lond B 1997;264:1471-9

68 Jacob S, McClintock MK, Zelano B, Ober C. Paternally inherited HLA alleles are associated with women's choice of male odor. Nat Genet 2002;30:175-9

69 Ober C, Weitkamp LR, Cox N, Dytch H, Kostyu D, Elias S. HLA and mate choice in humans. Am J Hum Genet 1997;61:497-504

70 Doty RL, Applebaum S, Zusho H, Settle RG. Sex differences in odor identification ability: a cross-cultural analysis. Neuropsychologia 1985;23:667-72

71 Doty RL. Gender and endocrine-related influences upon olfactory sensitivity. In: Meiselman HL, Rivlin RS (eds). Clinical Measurement of Taste and Smell. New York: Macmillan, 1986:377-413

72 Buss DM. The Evolution of Desire: Strategies of Human Mating. New York: Basic Books, 1994

73 Thomas MB, Haines SL, Akeson RA. Chemoreceptors expressed in taste, olfactory and male reproductive tissues. Gene 1996;178:1-5

74 Spehr M, Gisselmann G, Poplawski A, et al. Identification of a testicular odorant receptor mediating human sperm chemotaxis. Science 2003;299:2054-8 